\title{
Práticas estratégicas em uma rede de congregações religiosas: valores e instituições, interdependência e reciprocidade*
}

\author{
Cristiano de Oliveira Maciel** \\ Clóvis L. Machado-da-Silva***
}

SumÁrio: 1. Introdução; 2. Quadro teórico de referência; 3. Procedimentos metodológicos; 4. Análise dos dados e discussão dos resultados; 5. Considerações finais.

Summary: 1. Introduction; 2. Theoretical frame; 3. Methodological procedures; 4. Data analysis and results discussion; 5. Final remarks.

Palavras-chave: redes sociais; práticas estratégicas; organizações religiosas; teoria institucional.

KEY WORDs: social networks; strategic practices; religious organizations; institutional theory.

Neste artigo discorremos sobre a relação entre valores dos dirigentes, práticas estratégicas e imersão social de uma rede de congregações de confissão evangélica, estabelecida em Curitiba-PR, Brasil. O quadro teórico de referência no qual se apoia o trabalho articula a teoria institucional com a metodologia de análise de redes sociais e a abordagem da estratégia como prática. Consideramos 60 organizações religiosas na coleta de dados. A análise da rede revelou dois componentes que representam uma configuração do tipo centro-periferia dos padrões de relacionamentos entre os atores sociais. De modo geral, a relação entre contexto institucional, estrutura dos relacionamentos e atividades estratégicas aponta para a noção de interdependência

\footnotetext{
* Artigo recebido em jun. e aceito em set. 2009.

** Mestre em administração pelo Ceppad-UFPR. Doutorando em administração pelo PPAD/PUC-PR e professor assistente da PUC-PR. Endereço: Rua Professor Fernando Moreira, 124, ap. 706 - Centro — CEP 80410-120, Curitiba, PR, Brasil. E-mail: crmaciel.adm@gmail.com.

*** Doutor em administração institucional e mestre em fundamentos sociais e filosóficos pela Michigan State University - EUA. Professor titular do Ceppad/UFPR e PMDA/UP. Endereço: Av. Visconde de Guarapuava, 4487, ap. 4 - Batel — CEP 80240-010, Curitiba, PR, Brasil. E-mail: clms@terra.com.br.
} 
e reciprocidade. Verificamos que valores resultantes de diferentes lógicas de ação são reforçados pela direção da rede, no que concerne ao seu potencial normativo, para influenciar a interpretação dos seus membros e suas atividades estratégicas. No entanto, a configuração centro-periferia da rede de relacionamentos revela a necessidade de se reconhecer tanto a dinâmica quanto o caráter fragmentado do contexto institucional, uma vez que as relações sociais operam de modo recursivo na construção e reconstrução de ações organizacionais que atuam em direção à homogeneização institucional.

Strategic practices in a network of religious congregations: values and institutions, interdependence and reciprocity

In this article, we discuss the relationship between the values of managers, strategic practices and social embeddedness in a network of confessional evangelical congregations that is established in the city of Curitiba, Paraná state, Brazil. The theoretical frame of reference on which the study is based is the institutional theory, with the social network analysis methodology and the perspective of strategy as practice. We examined sixty religious organizations while collecting the data. The network analysis revealed two components that represent a central-peripheral type of configuration of relationship patterns among the social actors. In general, the relationship between institutional context, relationship structure and strategic activities points to the notion of interdependence and reciprocity. We found that values resulting from different logics of action are strengthened by the leadership of the network, concerning its normative potential, to influence the interpretation of its members and its strategic activities. Nevertheless, the central-peripheral configuration of the relationship network reveals the need for both the dynamic and the fragmented character of the institutional context to be recognized, since the social relationships operate recursively in the construction and reconstruction of organizational actions that move towards institutional homogenization.

\section{Introdução}

O que se rotula amplamente por sociedade organizacional assenta-se em uma concepção bem mais fragmentada do que a combinação das palavras sugere. Organizações públicas, empresas, sindicatos, organizações militares, ONGs e organizações religiosas configuram um amplo sistema social que agrega elementos com características e lógicas de operação bastante heterogêneas, apesar das aparentes similaridades. Em razão dessa complexidade, o estudo de organizações socialmente imersas em campos distintos deve merecer a atenção de pesquisadores.

No que concerne às organizações religiosas, a ocorrência de pesquisas empíricas é mais frequente na perspectiva da sociologia da religião. São raras 
as investigações que tratam de questões propriamente de natureza estratégica. Apenas mais recentemente alguns autores vêm debatendo a ideia de que organizações religiosas também operam em consonância com uma lógica concorrencial (Miller, 2002). Por exemplo: Warner (1993:1045), ao sugerir os contornos para um novo paradigma na sociologia da religião, busca estabelecer que o pressuposto-chave desse movimento centra-se na ideia de que organizações religiosas operam em um "mercado aberto".

De fato, vertentes religiosas com origem no cristianismo vêm desenvolvendo estratégias voltadas para o crescimento em decorrência da competição entre religiões e seitas. Nesse contexto, a adoção da forma organizacional em rede tem sido uma alternativa amplamente empregada. A partir dessa lógica, a competição é deslocada do âmbito de organizações isoladas para a concorrência entre redes interorganizacionais.

A principal consequência dessa ênfase nos relacionamentos interorganizacionais tem sido a necessidade de se considerar mais apropriadamente a questão da imersão social (embeddedness) das organizações (Granovetter, 1985). Nessa direção, a assertiva básica para o desenvolvimento deste estudo é que a questão da imersão social pode ser mais bem entendida ao se considerar ambas as facetas: a estrutural (Burt, 1992) e a institucional (Oliver, 1996). Essas duas faces remetem à natureza do fenômeno em suas bases estrutural $\mathrm{e}$ construcionista (Dacin, Ventresca e Beal, 1999; Uzzi, 1996 e 1997).

Em adição, faz-se necessário reconhecer que o fenômeno da imersão social se configura em meio ao relacionamento entre macro e micro de elementos que se constituem mutuamente num ambiente de maior amplitude. Cabe admitir, portanto, que instituições só se mantêm vivas mediante sua reprodução, bem como só podem ser transformadas por meio de práticas sociais.

Logo, a necessidade de se debruçar sobre as práticas sociais no nível micro exige perspectivas analíticas próprias, em razão da ênfase na persistência e (re)produção das instituições, que é dada no âmbito da teoria institucional. Em face desse desafio teórico e metodológico, um fundamento particularmente promissor vem sendo a abordagem da "prática" nos estudos organizacionais, que focaliza essencialmente as formas com que os atores interagem com as características sociais, e também físicas do seu contexto, no exercício de suas atividades estratégicas (Jarzabkowski, 2004 e 2005).

Nessa linha de análise, deixamos claro que a presente pesquisa trata tanto da forma, isto é, da configuração estrutural da rede interorganizacional, quanto dos valores e práticas sociais por ela condicionados (Powell e SmithDoerr, 1994), o que é delimitado aqui como a relação entre contexto dos sistemas sociais e práticas estratégicas dos agentes da rede. 
Um exame das interseções entre esses elementos é levado a efeito com a investigação sobre a relação que se estabelece entre valores dos dirigentes (pastores), oriundos do ambiente institucional, suas atividades estratégicas e a estrutura dos relacionamentos das congregações de uma igreja evangélica estabelecida na cidade de Curitiba-PR. Para tanto, este artigo está dividido em quatro seções principais, além desta introdução: quadro teórico de referência; procedimentos metodológicos; análise dos dados e discussão dos resultados; e considerações finais.

\section{Quadro teórico de referência}

Nesta seção são apresentados os principais contornos teóricos fundamentados nas noções de imersão social e prática estratégica. Esses conceitos são trabalhados e articulados especialmente na esfera de influência da teoria institucional.

\section{Imersão social}

A formação de redes organizacionais tem trazido para o campo da estratégia organizacional maior atenção para a imersão social das organizações. Esse fenômeno tem sido tratado em diversos aspectos sob a égide do conceito mais amplo de embeddedness (Granovetter, 1985). Tal conceito, no que concerne à análise das organizações, pode ser entendido como imbricamento ou imersão da atividade econômica dos agentes num contexto mais amplo de relações sociais.

$\mathrm{O}$ argumento por detrás do termo sustenta que o comportamento organizacional está imerso em processos e relações sociais de tal forma que tratálos como aspectos independentes levaria a sérias limitações na apreensão da dinâmica das atividades organizacionais (Granovetter, 1985). Assim, em sua ênfase estrutural predomina a abordagem da análise de redes.

No que tange às suas propriedades analíticas, essa perspectiva tem origem na psicologia, na sociologia e na teoria das organizações, focalizando as relações sociais internas da organização, as relações entre organizações ou o ambiente das organizações como um todo (Powell e Smith-Doerr, 1994). Nesse enfoque, interessa delimitar a posição do ator organizacional na rede, a qual revela funções de habilitação e de coerção da ação dos atores organizacionais ou, então, verificar como determinado arranjo estrutural entre organizações gera benefícios e oportunidades (Burt, 1992). 
A abordagem de redes, quando se debruça sobre a dimensão institucional, enfatiza regras e normas, crenças e valores, pressupondo a rede como forma de governança das ligações de interdependência em uma indústria, campo ou arranjo estrutural. Essa interdependência é caracterizada por contratos relacionais, produção conjunta e outras formas de alianças e mecanismos de coordenação e controle (Powell e Smith-Doerr, 1994).

Em resumo, Powell e Smith-Doerr (1994) concluem defendendo uma posição que considere essas duas abordagens na busca de investigações que possam colocar em exame tanto a forma quanto o conteúdo da rede, buscando aprofundar a apreensão das ênfases estrutural e institucional, bem como as interseções entre as duas correntes de investigação. Tal assertiva parece mais evidente quando se considera que a ação social só pode ocorrer em uma arena social normativa, ou seja, em uma estrutura de relacionamentos. A presença de uma configuração de atores supõe uma arena que só é normativa e de natureza social quando existem instituições que regem o comportamento dos atores nessa rede.

Em razão da necessidade de estabelecer as bases para investigação do contexto normativo, a perspectiva institucional de análise merece destaque neste artigo. No plano propriamente organizacional, principalmente à luz da vertente cultural-cognitiva da teoria institucional, pesquisadores entendem que crenças e valores racionalizados na sociedade orientam o funcionamento das organizações. Ao serem atendidas as exigências desses padrões, as organizações obtêm legitimidade para suas atividades, aumentando suas possibilidades de sobrevivência, independentemente de sua eficiência e da demanda por seus produtos.

Nessa direção, admite-se que a conformidade parece condicionar mais frequentemente a sobrevivência das organizações do que a eficiência (Meyer e Rowan, 1977). Em consequência do processo de adoção das mesmas práticas de uma organização por outras, em busca de legitimidade, emerge o isomorfismo de estruturas, processos e estratégias (Dimaggio e Powell, 1983).

Todavia, em alinhamento com a ideia de reciprocidade entre agência e estrutura está a possibilidade tanto de manutenção quanto de alteração de propriedades estruturais. Sobretudo quando se reconhece que práticas, estruturas e estratégias organizacionais não são levadas a cabo de maneira uniforme por todas as organizações em um mesmo campo. Certo grau de heterogeneidade é atribuído à capacidade de agência dos atores sociais, que incorpora os recursos e a interpretação dos agentes. Com essa observação, Machado-daSilva, Fonseca e Crubellate (2005:26) defendem uma abordagem recursiva do processo de institucionalização, afirmando que ele "não pode ser plenamente 
apreendido sem que a interpretação da ação seja evidenciada como o aspecto que possibilita o seu desenvolvimento".

O que deve ficar evidente nessa abordagem é que a reprodução e transformação das organizações e do ambiente são consideradas, essencialmente, no plano cultural-cognitivo. Nesse sentido, as organizações são vistas como sistemas de interpretação (Bartunek, 1984; Daft e Weick, 1984), que se fundamentam em um conjunto de crenças e valores compartilhados, atribuindo significados a determinados objetos e situações. Dentro dessa lógica, Machado-da-Silva, Fonseca e Crubellate (2005:21) entendem que "mediante referências institucionais se encontram ações racionalmente limitadas".

Como lembram Daft e Weick (1984), as organizações precisam efetivamente fazer interpretações do seu ambiente. Com frequência faz-se necessário que decisores organizacionais adentrem num conjunto de eventos presentes em seu contexto ambiental para que, a partir deles, possam construir sentido no interior das organizações e manter ou transformar esses significados fora delas visando à ação organizacional. Em decorrência da interdependência entre interpretação e ação dos atores sociais, o próximo tópico explora a noção de estratégia como prática social.

\section{Estratégia como prática}

A estratégia enquanto prática social é delimitada por um conjunto de interpretações, interações e atividades dos atores envolvidos nas ações estratégicas e, por isso, não dissocia pensamento e ação. Tais interações abastecem uma base de significação para a ação organizacional (Jarzabkowski, 2003).

O enquadramento das ações estratégicas em uma ou outra escola de pensamento deixa muito a desejar, principalmente aos acadêmicos, que se encontram na busca do entendimento dessa atividade. Os estrategistas parecem desempenhar suas práticas de forma mais específica e de acordo com as idiossincrasias dos seus contextos particulares, com várias combinações dos modelos (Whittington, 1996, 2004 e 2006).

A partir desse argumento, alguns autores vêm propondo a visão baseada em atividades (VBA) para o exame da ação estratégica em seus diversos níveis (Jarzabkowski, 2004 e 2005; Johnson, Melin e Whittington, 2003).

Desse modo, a estratégia organizacional é concebida em meio a um conjunto de atividades voltadas para a mobilização de recursos tangíveis e intangíveis, e intencionalmente orientadas a qualquer objetivo associado ao desempenho organizacional em termos econômicos e sociais. 
Por conseguinte, nessa lógica ocorre claramente um deslocamento de ênfase do plano das ideias para o plano da ação, em uma versão menos atomizada, para o estudo da ação organizacional, pois uma perspectiva micro da estratégia exige que a atenção se volte para as atividades estratégicas.

A visão baseada em atividades coloca "ênfase sobre processos e práticas detalhadas, quais constituem as atividades diárias da vida organizacional e quais se relacionam aos resultados estratégicos" (Johnson, Melin e Whittington, 2003:3). É o conjunto de atividades organizacionais que constrói a estratégia (Jarzabkowski, 2004).

Ao considerar a atividade estratégica, Jarzabkowski (2004) emprestalhe ênfase como uma prática socialmente construída, algo que as pessoas fazem e, portanto, mudam ou procuram mantê-la. As várias abordagens que se debruçam sobre a dimensão prática da ação têm em comum uma ênfase sobre as formas como os atores interagem com as características físicas e sociais de seu contexto (Jarzabkowski, 2004 e 2005).

Com foco na questão da agência e na interdependência entre atores e instituições sociais é possível sugerir que práticas estratégicas recursivas e adaptativas representam característica fundamental para o desenvolvimento e manutenção das instituições. O que se espera salientar é que a ênfase na prática estratégica como uma ação social possibilita examinar, de modo mais abrangente, as estratégias organizacionais, incluindo tanto elementos mercadológicos e estritamente objetivos, quanto aqueles ligados a uma ótica de investigação de natureza simbólica.

\section{Articulando imersão social e atividades estratégicas}

O pressuposto subjacente à ótica de análise empregada aqui se assenta na lógica weberiana de que a ação social só pode ser entendida como tal quando for dotada de sentido. E, para tanto, exige considerar o outro. Tal assertiva revela duas faces de uma mesma moeda. Por um lado, existe invariavelmente a necessidade de uma arena normativa, constituída e constantemente reconstruída pelas ações dos atores sociais, para que possa haver ação social. Nesse sentido, a ação social só pode ocorrer em uma rede de relações.

Admitindo essa lógica de argumentação, é possível inferir que todas as organizações encontram-se socialmente imersas, tanto na forma estrutural quanto na forma institucional. Considerando organizações com estruturas em rede, talvez a característica primordial para os agentes desse arranjo seja o fato de que a participação em uma rede de cooperação deliberadamente 
planejada signifique a inserção de uma estrutura institucional adicional ao contexto institucional que opera no nível de campo organizacional.

Assim, a inserção do contexto institucional no nível da rede significa a articulação de processos multiníveis que podem impactar nas ações organizacionais de diversas maneiras. Esse outro contexto de referência se traduz na presença de um contexto institucional de segunda ordem (nível de rede interorganizacional), que se articula positiva ou negativamente com o contexto institucional de primeira ordem (nível de campo organizacional).

Nesses termos, uma perspectiva voltada à prática possibilita um tratamento da estratégia como atividade socialmente imersa em seu contexto físico e social, bem como possibilita entender essas ações em uma ótica relacional.

Essa lógica de análise incorpora as interseções e a reciprocidade entre o contexto institucional das organizações insertas em uma rede organizacional, o contexto institucional no nível da rede, a configuração da rede entre os elementos do arranjo e ações estratégicas dos atores da estrutura em rede.

A partir das interações desses elementos é possível observar a articulação entre embeddedness institucional no nível de campo organizacional e no nível de uma rede, embeddedness estrutural (estrutura dos relacionamentos) e estratégia.

Tal articulação evidencia a necessidade de uma ótica de investigação que opere em múltiplos níveis de análise. Evidencia ainda a reciprocidade entre agência e estrutura (Giddens, 1989), que se traduz em uma abordagem coevolucionária (Sydow e Windeler, 1998) quando da inserção na análise de um sistema de relações deliberadamente planejado, que amplia o espaço para práticas estratégicas tanto recursivas quanto adaptativas.

De modo geral, o argumento que se tenta estabelecer aqui é que a integração da teoria institucional, redes sociais e a abordagem da estratégia como prática direcionam atenção, sobretudo à imersão social das práticas organizacionais de natureza estratégica.

Como argumentam Sydow e Windeler (1998), pela perspectiva das teorias que se ocupam do fenômeno do embeddedness, as práticas são compreendidas como socialmente imersas em seus contextos e tais contextos são visualizados em diversos níveis, como: sociedade, indústria e rede. E, diferentemente de muitas teorias econômicas, admite-se nessa linha de investigação que as práticas são recursivamente relacionadas a tais esferas contextuais.

Logo, com o objetivo de verificar a relação que foi até aqui teoricamente sustentada entre embeddedness (imersão social), valores que condicionam a interpretação dos dirigentes e suas práticas estratégicas, foi realizada uma investigação empírica no contexto de uma rede de congregações de uma igreja 
evangélica. Assim, foi possível verificar as influências entre ambiente institucional das organizações religiosas, ambiente institucional mais ou menos manipulado pela direção da rede, os valores nos esquemas interpretativos dos dirigentes a partir desses mecanismos e suas decorrentes atividades estratégicas. O estudo foi norteado pelos procedimentos metodológicos que se encontram detalhados na próxima seção.

\section{Procedimentos metodológicos}

A caracterização ou delineamento da pesquisa remete à noção de plano geral que explicita um modelo conceitual e operacional de estudo. Esse plano envolve mais frequentemente tipo de pesquisa, concepção, sua definição temporal, nível e unidade de análise (Babbie, 1998; Creswell, 2003).

A análise de redes é o método empregado no estudo (Hanneman, 2001). No que concerne à concepção de pesquisa, este estudo tem objetivos de descrição (Babbie, 1998; Creswell, 2003).

Para obtenção dos dados fez-se uso de uma abordagem qualitativa em uma fase preparatória, com o objetivo de coletar informações para o desenvolvimento do questionário, e uma fase quantitativa para avaliar as possíveis relações entre os elementos de interesse presentes na investigação. Logo, foram combinados procedimentos qualitativos e quantitativos para obtenção de dados, sem necessariamente buscar convergência de diferentes fontes.

A primeira etapa consistiu em uma pesquisa documental de periódicos, livros, jornais, informes, panfletos e notícias do Jornal Nacional da TV Globo. Esse estágio permitiu o delineamento do contexto institucional de primeira ordem, ou seja, das regras, normas e pressupostos mais significativos que operam no campo das organizações religiosas no país.

O tratamento de dados dessa primeira etapa consistiu em análises qualitativa e quantitativa (estatística lexical) de conteúdo (Bardin, 1977) dos dados secundários para o delineamento do contexto institucional de primeira ordem. A análise de conteúdo ocorreu via agrupamento das notícias, de acordo com a similaridade das mensagens. Posteriormente, foram extraídos grupos de ações que pudessem refletir a lógica por detrás das atividades das organizações religiosas no país e assim revelar uma descrição do contexto institucional.

Para a descrição do contexto institucional de segunda ordem (nível da rede) foram realizadas, além da análise de documentos, um total de sete entrevistas semiestruturadas (Flick, 2004) com seis dirigentes de algumas das congregações em Curitiba. Tais entrevistas contribuíram para a identificação 
dos valores mais disseminados pela administração da rede e das atividades tidas como estratégicas, ou seja, orientadas para objetivos associados ao desempenho das congregações. Por motivos de saúde, não foi possível entrevistar o presidente da igreja em Curitiba, nem seu vice-presidente, que está afastado, no momento, em virtude de conflitos internos.

O tratamento de dados dessa segunda etapa se deu por meio das transcrições das entrevistas e posterior análise de conteúdo (Bardin, 1977). Após o processo de análise dos dados qualitativos foi formulado o questionário estruturado (Babbie, 1998; Wasserman e Faust, 1999) para o levantamento do grau de presença das características do contexto institucional (primeira ordem e segunda ordem) nos esquemas interpretativos; da presença das atividades estratégicas em cada congregação; e identificação dos relacionamentos entre os membros da rede.

A dimensão ou amplitude temporal do trabalho se assenta em um corte seccional (transversal). O nível de análise é o da rede e a unidade de análise adotada é a organização.

O universo da pesquisa é composto por 167 congregações da rede de organizações religiosas. Em face do número de organizações e do objetivo de mapeamento da configuração da rede, optou-se por realizar um levantamento envolvendo todas as organizações.

Entretanto, quando não foi efetivada a proposta de censo, foi empregado o critério de amostragem autogerada. Esse critério amostral exigiu que fossem investigados sempre aqueles dirigentes que tiveram seu nome relatado por outro pastor durante a fase de levantamento. A amostra final do estudo compreendeu um total de 60 dirigentes.

\section{Análise dos dados e discussão dos resultados}

A análise qualitativa de conteúdo dos dados secundários revelou 12 valores mais significativos relacionados à gestão das organizações religiosas no país (contexto institucional de primeira ordem) e que podem ser apresentados nos seguintes fatores:

$\checkmark$ relacionamento e inserção política;

v expansão da igreja;

v competição religiosa;

$\checkmark$ responsabilidade social;

$\checkmark$ modernidade; 
$\checkmark$ eficiência;

v customização;

v qualidade;

- valorização do mercado cristão;

v reputação;

- tradição;

v colaboração interorganizacional.

A partir da análise das entrevistas semiestruturadas com os dirigentes de congregação verificou-se que os 12 valores descritos no contexto institucional de primeira ordem estavam todos presentes no nível da rede. Porém, os princípios mais disseminados pela administração central da rede (contexto institucional de segunda ordem) são:

v expansão da igreja;

v responsabilidade social;

$\checkmark$ modernidade;

$\checkmark$ eficiência;

v customização;

$\checkmark$ qualidade;

- reputação;

$\checkmark$ tradição;

v colaboração interorganizacional.

A busca por uma análise das atividades (Jarzabkowski, 2005; Whittington, 2006) consideradas estratégicas apontou que o desempenho estratégico das organizações da rede em Curitiba poderia ser avaliado a partir de:

v crescimento no número de pessoas que são convertidas;

v que frequentam o culto;

v que pagam o dízimo;

que vivem de acordo com a "Palavra" (Bíblia);

v que são batizadas nas águas. 
Durante as entrevistas, os pastores foram questionados sobre práticas que considerassem essenciais para alcançar esses objetivos. Após as entrevistas, foram realizadas duas revisões com os pastores para avaliar, entre as atividades identificadas, quais seriam realmente estratégicas e poderiam não estar presentes em todas as congregações. Entre mais de 50 atividades, 36 foram apontadas como estratégicas (tabela 4), considerando os cinco objetivos associados ao desempenho das congregações. Fonte dos dados, período analisado, número de arquivos e tratamento empregado na análise constam no quadro.

Fontes e tratamento dos dados qualitativos

\begin{tabular}{|c|c|c|c|}
\hline Objetivo & Fonte dos dados & $\begin{array}{l}\text { Período/no de } \\
\text { arquivos }\end{array}$ & $\begin{array}{c}\text { Tratamento dos } \\
\text { dados }\end{array}$ \\
\hline \multirow{8}{*}{$\begin{array}{l}\text { Descrição do contexto } \\
\text { institucional de primeira } \\
\text { ordem (valores } \\
\text { ambientais) }\end{array}$} & Site IBGE & $\begin{array}{l}\text { 10-9-2006 (três } \\
\text { planilhas eletrônicas) }\end{array}$ & Análise de conteúdo \\
\hline & Site Sepal & $\begin{array}{l}\text { 10-9-2006 (quatro } \\
\text { arquivos) }\end{array}$ & Análise de conteúdo \\
\hline & $\begin{array}{l}\text { Jornal Folha de } \\
\text { S.Paulo }\end{array}$ & $\begin{array}{l}2004 \text { a } 2006 \text { (1.088 } \\
\text { arquivos) }\end{array}$ & Análise de conteúdo \\
\hline & Jornal Gazeta do Povo & $\begin{array}{l}2004 \text { a } 2006 \text { (583 } \\
\text { arquivos) }\end{array}$ & Análise de conteúdo \\
\hline & Revista Veja & 137 arquivos & Análise de conteúdo \\
\hline & Revista Exame & $\begin{array}{l}1997 \text { a } 2006 \text { (19 } \\
\text { arquivos) }\end{array}$ & Análise de conteúdo \\
\hline & $\begin{array}{l}\text { Artigos científicos e } \\
\text { livros }\end{array}$ & Diversos (35 arquivos) & Análise de conteúdo \\
\hline & Jornal Nacional (TV) & $\begin{array}{l}2002 \text { a } 2006 \text { (162 } \\
\text { arquivos) }\end{array}$ & $\begin{array}{l}\text { Análise de conteúdo } \\
\text { (estatística lexical) }\end{array}$ \\
\hline \multirow{3}{*}{$\begin{array}{l}\text { Descrição do contexto } \\
\text { institucional de segunda } \\
\text { ordem (valores no nível } \\
\text { da rede) }\end{array}$} & $\begin{array}{l}\text { Entrevistas com } \\
\text { dirigentes de igrejas }\end{array}$ & $\begin{array}{l}11-10 \text { a } 7-11 \text { de } 2006 \\
\text { (sete entrevistas) }\end{array}$ & Análise de conteúdo \\
\hline & $\begin{array}{l}\text { Estatutos da rede } \\
\text { nacional e de Curitiba }\end{array}$ & $\begin{array}{l}\text { 10-12-2006 (dois } \\
\text { arquivos) }\end{array}$ & Análise de conteúdo \\
\hline & $\begin{array}{l}\text { Site da rede em } \\
\text { Curitiba }\end{array}$ & $\begin{array}{l}\text { 10-9-2006 (sete } \\
\text { arquivos) }\end{array}$ & Análise de conteúdo \\
\hline
\end{tabular}




\begin{tabular}{|c|c|c|c|}
\hline Objetivo & Fonte dos dados & $\begin{array}{l}\text { Período/no de } \\
\text { arquivos }\end{array}$ & $\begin{array}{l}\text { Tratamento dos } \\
\text { dados }\end{array}$ \\
\hline \multirow[t]{5}{*}{$\begin{array}{l}\text { Descrição das ações } \\
\text { estratégicas }\end{array}$} & $\begin{array}{l}\text { Entrevistas com } \\
\text { dirigentes de igrejas }\end{array}$ & $\begin{array}{l}11-10 \text { a } 7-11 \text { de } 2006 \\
\text { (sete entrevistas) }\end{array}$ & Análise de conteúdo \\
\hline & Folhetos & $\begin{array}{l}2006 \text { (42 } \\
\text { documentos) }\end{array}$ & Análise de conteúdo \\
\hline & Informativos & $\begin{array}{l}2006 \text { (sete } \\
\text { documentos) }\end{array}$ & Análise de conteúdo \\
\hline & Cadernos bíblicos & $\begin{array}{l}2006 \text { ( } 13 \\
\text { documentos) }\end{array}$ & Análise de conteúdo \\
\hline & $\begin{array}{l}\text { Jornais de outras } \\
\text { igrejas }\end{array}$ & $\begin{array}{l}2006 \text { (nove } \\
\text { documentos) }\end{array}$ & Análise de conteúdo \\
\hline
\end{tabular}

Depois da descrição dos valores do contexto institucional que poderiam estar presentes nos esquemas interpretativos dos dirigentes das congregações e da identificação das atividades estratégicas foi construído o questionário estruturado a ser aplicado posteriormente.

O questionário inicial foi elaborado com quatro questões para mensuração de cada um dos 12 valores ambientais, totalizando 48 questões. Para uma avaliação das propriedades psicométricas das escalas, as questões sobre valores foram aplicadas em uma amostra de 120 fiéis católicos e evangélicos. Após a aplicação de uma análise fatorial exploratória (AFE) e cálculo do alfa de Cronbach (Hair Jr. et al., 1995) foi possível realizar uma redução dos indicadores de cada um dos fatores. Dessa maneira, o novo questionário agregou 36 indicadores para mensuração do grau de concordância com os 12 valores ambientais, 36 questões sobre as atividades estratégicas e outras questões para levantamento dos dados pessoais dos dirigentes. No mesmo instrumento os pastores podiam indicar os nomes dos pastores de outras congregações da rede que eles mantinham contato mais frequente. Com o instrumento de coleta de dados finalizado ocorreu a aplicação de 60 questionários por meio de contato pessoal com os dirigentes. Os indicadores de valores foram mensurados com escala de Likert e as atividades estratégicas eram opções que poderiam ou não ser marcadas pelo pastor.

Uma análise descritiva das características da amostra apontou que, dos 60 entrevistados, 11 são evangelistas (um nível abaixo da função pastor) e 49 são efetivamente pastores. Em relação à idade, a média $(\bar{x})$ é de 54 , com amplitude de 28 a 82 anos.

Na sequência foram avaliadas as escalas de mensuração da presença dos valores ambientais nos esquemas interpretativos dos dirigentes que fizeram 
parte da pesquisa. Essa etapa de análise foi realizada essencialmente com objetivo de assegurar a validade e confiabilidade das medidas (Guilford, 1954) que seriam utilizadas nas análises posteriores.

Depois da verificação de certa aproximação da distribuição dos dados intervalares com a curva normal, foi realizada uma análise fatorial exploratória que apresentou como resultado 12 fatores. A extração do número de fatores foi definida a priori. Os resultados comprovaram a unidimensionalidade de cada fator, bem como bons índices de consistência interna (alfa de Cronbach). O emprego da técnica fatorial foi julgado adequado em função do índice de $\mathrm{KMO}=0,678$ e do teste de Bartlett ( $p$-value $<0,01)$ que indicaram um número suficiente de correlações entre os indicadores das escalas. As medidas de consistência interna dos fatores e as estatísticas univariantes figuram na tabela 1 .

Tabela 1

Alfa de Cronbach e estatísticas descritivas para os fatores da escala de valores

\begin{tabular}{|lcccc|}
\hline & $\begin{array}{c}\text { Alfa de } \\
\text { Cronbach }\end{array}$ & $\begin{array}{c}\text { Média } \\
(\bar{x})\end{array}$ & $\begin{array}{c}\text { Desvio-padrão } \\
(\mathbf{s})\end{array}$ & $\begin{array}{c}\text { Mediana } \\
\left(\mathbf{M}_{\mathrm{d}}\right)\end{array}$ \\
\hline F01 - Inserção política & 0,964 & 4,10 & 3,286 & 2,83 \\
F02 - Expansão & 0,954 & 7,97 & 1,804 & 8,67 \\
F03 - Responsabilidade social & 0,935 & 7,67 & 1,966 & 8,00 \\
F04 - Modernidade & 0,983 & 6,96 & 2,800 & 7,00 \\
F05 - Eficiência (gestão) & 0,972 & 6,77 & 2,567 & 7,50 \\
F06 - Customização & 0,974 & 5,71 & 3,075 & 6,84 \\
F07 - Qualidade & 0,904 & 9,17 & 0,823 & 9,33 \\
F08 - Reputação & 0,905 & 8,84 & 1,071 & 9,00 \\
F09 - Tradição & 0,985 & 7,49 & 2,314 & 8,00 \\
F10 - Cooperação & 0,972 & 7,77 & 1,598 & 8,00 \\
F11 - Competição & 0,984 & 4,99 & 2,801 & 4,00 \\
F12 - Mercado & 0,980 & 3,73 & 2,613 & 3,00 \\
\hline
\end{tabular}

Fonte: Dados primários da pesquisa.

O grau de valorização desses fatores por parte dos dirigentes parece estar associado ao grau de institucionalização dos valores disseminados pela administração central da rede. Como foi descrito na análise dos dados qualitativos, a sede ou congregação central, por meio de sua direção, historicamente 
tem estimulado seus pastores a se preocupar e a dar maior atenção aos seguintes fatores:

จ expansão da igreja;

$\checkmark$ qualidade;

v responsabilidade social;

$\checkmark$ reputação;

v tradição;

$\checkmark$ eficiência;

$\checkmark$ modernidade;

v cooperação entre congregações.

A customização é um dos valores menos estimulados pela central. Quanto à inserção política, a direção tenta assumir uma posição neutra e a valorização do mercado cristão e da competição não ocorre de forma deliberada. Vale destacar que a média desses últimos fatores: customização, inserção política, mercado e competição são as mais baixas, comparados àqueles que parecem ser disseminados explicitamente pela central. Decorre daí que as províncias de significado da direção da central parecem se associar ao grau de valorização de determinados fatores. Ademais, a estrutura no nível da rede ou, como proposto supra, contexto institucional de segunda ordem, pode potencializar a importância e legitimidade de alguns valores ambientais relacionados à gestão e amortecer outros que são percebidos como indesejáveis.

Uma explicação plausível para a relação que se verifica entre contexto institucional de primeira e de segunda é que arranjos estruturais, que de modo voluntarista dão forma ao seu próprio sistema relacional, não operam num vácuo social. Tais estruturas têm pouca margem de ação fora dos limites impostos por um contexto institucional de espectro mais amplo. Entretanto, se esse contexto impõe limites, ao mesmo tempo abre caminhos legítimos para institucionalização de valores, como a modernidade e a eficiência.

Além da análise univariada dos fatores ambientais presentes nos esquemas interpretativos dos dirigentes das congregações, pareceu conveniente a realização de uma análise de correlação que pudesse sugerir associações entre os diferentes valores.

Ao assumir um grau de significância $p$-value $<0,05$, muitas variáveis aparecem associadas. Sem pretensão de estabelecer causalidades, algumas 
relações mais interessantes devem ser comentadas. A inserção política está levemente associada à eficiência $(r=0,297)$. Essa relação pode indicar que a institucionalização da lógica de eficiência por meio da gestão está relacionada a outros valores, como a inserção política. Expansão apresenta um $r=0,600$ com o fator modernidade e $r=0,590$ com eficiência. A busca pelo crescimento da igreja pode estar atrelada aos princípios mais modernos das organizações de natureza comercial.

A responsabilidade social se associa positivamente com modernidade $(r$ $=0,311)$, eficiência $(r=0,385)$, customização $(r=0,357)$, competição $(r=$ $0,411)$ e mercado $(r=0,315)$. Ao contrário do que as ações da igreja, voltadas para a comunidade, podem sugerir, existe a possibilidade de que essas iniciativas continuem sendo praticadas como há muito tempo, porém, com uma lógica distinta, fundamentada não mais apenas no altruísmo, mas também em critérios de competitividade e formas de atendimento das necessidades de segmentos de fiéis em particular.

A modernidade também se associa com eficiência $(r=0,663)$, customização $(r=0,513)$, competição $(r=0,265)$, cooperação $(r=0,317)$ e mercado $(r=0,413)$. A eficiência está bastante associada à customização $(r=$ $0,680)$, e também se relaciona com cooperação $(r=0,426)$, mercado $(r=$ $0,430)$ e competição $(r=0,263)$. A customização apresenta correlação positiva mais acentuada com competição $(r=0,321)$. Competição e mercado também aparecem associados positivamente $(r=0,447)$. Esse conjunto de valores representa a lógica de ação das organizações religiosas contemporâneas que caracterizam o cristianismo.

Os valores qualidade, tradição e reputação estão positivamente associados apenas entre si. Qualidade tem um $r=0,483$ com tradição e $r=0,520$ com reputação. Tradição e reputação apresentam um $r=0,501$. Esses últimos três valores apresentam associações com sentido negativo em relação a todos os outros valores, porém, nem todas estatisticamente significativas. Qualidade tem as associações negativas estatisticamente significativas e mais fortes com customização $(r=-0,355)$ e eficiência $(r=-0,323)$. Tradição tem coeficiente de correlação negativo e mais acentuado com eficiência $(r=-0,523)$, com customização $(r=$ $-0,478)$, com modernidade $(r=-0,452)$ e inserção política $(r=-0,352)$. E a valorização da reputação é inversamente associada, principalmente, à política $(r=-0,392)$, modernidade $(r=-0,379)$, eficiência $(r=-0,353)$ e customização $(r=-0,302)$.

Logo, mesmo evitando tratar de causalidades entre essas variáveis, é razoável supor que valores como expansão, responsabilidade social, moder- 
nidade, eficiência, customização e, menos fortemente, competição, mercado e cooperação, não só apresentam covariância compartilhada como acabam por reforçar uns aos outros. O que pode ocorrer por conveniência ou evitação de outros valores que operam de forma diametralmente oposta, como: tradição, reputação e qualidade. À medida que a legitimidade da preocupação com a tradição dos costumes, com a reputação da igreja e pastores e com a qualidade dos cultos se faz imperiosa, valores como modernidade, eficiência e customização tendem a ser julgados como mais desejáveis quando encontram suporte cognitivo em outros valores de lógica aparentemente semelhante, como expansão, competição e mercado. Nesses termos, padrões institucionais de lógicas tanto semelhantes quanto distintas parecem contribuir concomitantemente à desinstitucionalização e à sedimentação dos valores presentes nesse arranjo.

Em adição, os dados relacionais (contatos entre os dirigentes das congregações) foram submetidos a uma análise de suas principais propriedades estruturais. Essa forma de análise objetivou investigar a presença ou ausência de padrões de relacionamentos entre os atores da rede para que fosse possível a descrição das interações entre a noção de imersão social, em suas facetas: institucional e estrutural (Burt, 1992; Oliver, 1996; Uzzi, 1996 e 1997) e as atividades estratégicas (Jarzabkowski, 2005) dos nós (agentes) da rede (pastores).

Com o auxílio do programa Ucinet 6 foi analisada a matriz simétrica dos dados relacionais. A densidade de 0,0723 revelou uma rede bastante fluida, o que indica baixa coesão entre os membros da rede como um todo. Logo, optouse por uma análise mais apropriada acerca da coesão de diferentes grupos no interior da rede. Com auxílio da técnica de escalonamento multidimensional verificou-se que havia possibilidade de identificação de grupos mais coesos. Na sequência, foi realizada uma análise de cluster pelo método simple average, o qual indicou a existência de uma série de grupos. Entretanto, uma análise da homogeneidade dos grupos não indicou suficiente homogeneidade no interior de dois ou mais clusters. Dessa maneira deu-se preferência para uma análise centro-periferia (Borgatti e Everett, 1999), a qual parte do princípio que talvez exista apenas um grupo suficientemente homogêneo e com os demais nós da rede frouxamente conectados ao núcleo do arranjo relacional. O resultado da análise centro-periferia mostrou-se mais adequado para fins de aglomeração de alguns atores da rede. O sociograma extraído por meio do programa Pajek resultou da análise que aparece na figura. 


\section{Sociograma centro-periferia}

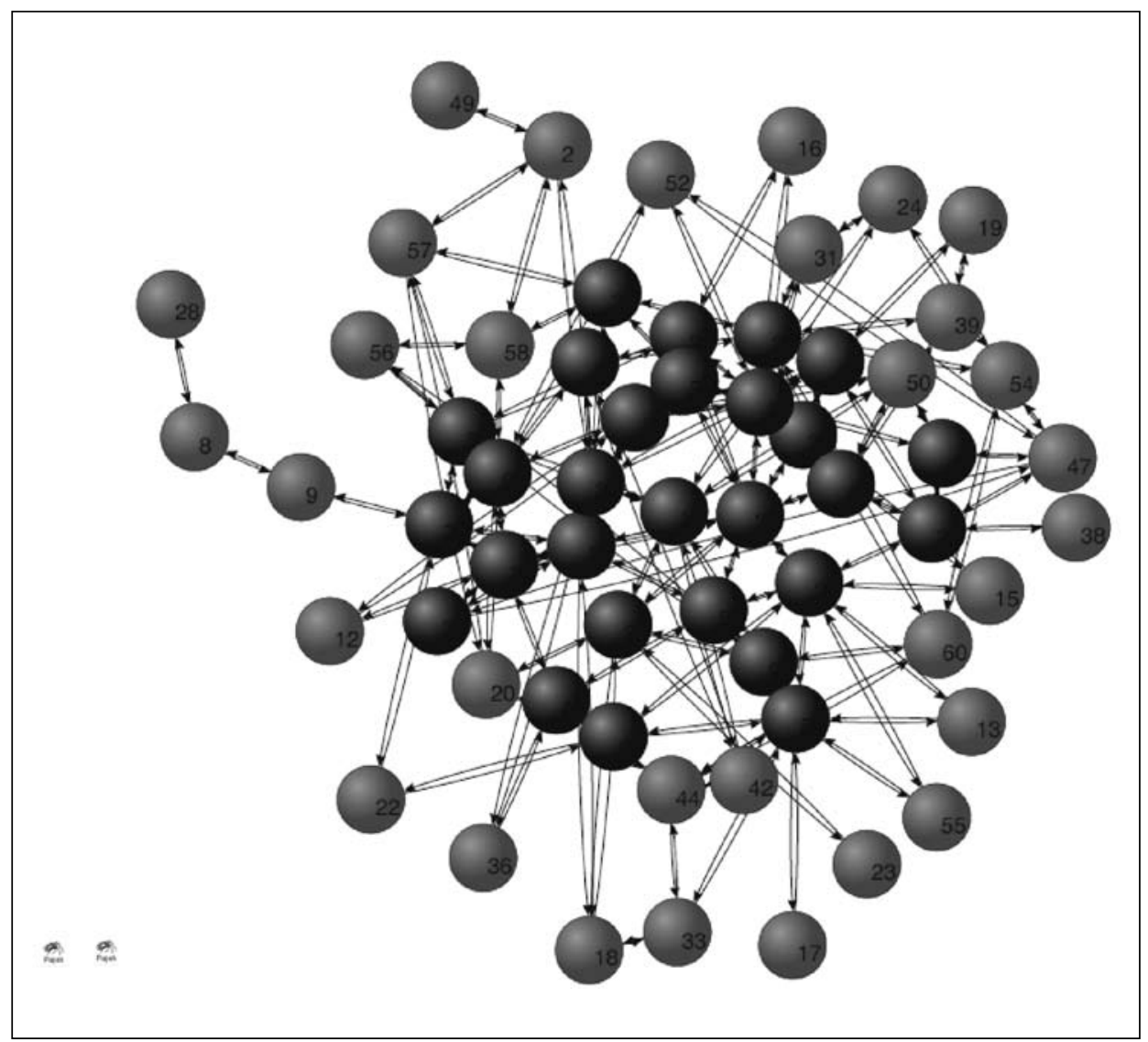

Fonte: Dados primários tratados no Pajek.

Como sugere a figura, um grupo de dirigentes é mais central, com mais alta densidade e maior centralização; o outro grupo tem seus nós dispersos em torno do centro. O componente central da rede (nós em tom mais escuro) conta com 28 dirigentes de congregações e o componente periférico (nós com cor mais clara) agrega 32 pastores. Desse modo, os resultados da análise sugerem haver espaços dentro da rede que figuram como lócus de desintegração em relação a crenças e valores, que refletem algum grau de estratificação social em função da falta de coesão (Borgatti e Everett, 1999).

Por conseguinte, foi analisada a centralidade de grau (degree centrality) maior número de contatos - e de intermediação (betweenness centrality) - maior capacidade em mediar contatos entre os atores da rede. Como o número de laços variou de 1 a 11, os coeficientes de centralidade foram bas- 
tante diversos. Desse modo, inferiu-se que a centralidade dos nós da rede pode figurar como uma variável associada aos valores. O pressuposto aqui é que agentes da rede com valores mais legítimos em determinado arranjo controlem maior número de laços com o restante dos atores da rede.

São outros atores sociais, a partir de suas crenças e valores, que dão forma e constroem de maneira recursiva o cenário social constituído por regras, normas e pressupostos que servem de base para a interpretação. Crenças e valores cristalizados e racionalizados na sociedade ou em subsistemas sociais acabam por orientar a ação. A serem atendidas as exigências desses padrões, os atores sociais são premiados com a legitimidade para suas atividades, garantindo assim sua aceitação (Dimaggio e Powell, 1983; Scott, 2001). A rede de relacionamentos entre esses dirigentes é fonte de legitimidade. São outros agentes que atribuem significado e dignidade normativa às práticas desses atores.

A partir desse raciocínio, os coeficientes de centralidade dos atores da rede e suas médias para os valores ambientais foram submetidos a uma análise de correlação. Os coeficientes de correlação $(r)$ e significância estatística correspondente figuram na tabela 2 .

Tabela 2

Correlações entre valores e medidas de centralidade

\begin{tabular}{|llc|}
\hline & Degree & Betweenness \\
\hline F01 - Inserção política & 0,155 & 0,086 \\
F02 - Expansão & 0,177 & $0,222^{*}$ \\
F03 - Responsabilidade social & $0,227^{*}$ & $0,234^{*}$ \\
F04 - Modernidade & 0,189 & $0,216^{*}$ \\
F05 - Eficiência (gestão) & $0,377^{* * *}$ & $0,394^{* * *}$ \\
F06 - Customização & 0,196 & $0,277^{* *}$ \\
F07 - Qualidade & $-0,514^{* * *}$ & $-0,465^{* * *}$ \\
F08 - Reputação & $-0,323^{* * *}$ & $-0,217^{*}$ \\
F09 - Tradição & $-0,323^{* *}$ & $-0,250^{*}$ \\
F10 - Cooperação & $0,248^{*}$ & $0,241^{*}$ \\
F11 - Competição & $0,328^{* *}$ & 0,192 \\
F12 - Mercado & $0,345^{* * *}$ & $0,274^{* *}$ \\
\hline
\end{tabular}

Fonte: Dados primários da pesquisa.

${ }^{*} p$-value $<0,10$

*** $p$-value $<0,05$

*** p-value $<0,01$ 
Os resultados na tabela de correlação indicam que o grau de centralização dos dirigentes das congregações da central está mais significativo e positivamente associado com os seguintes valores: eficiência, mercado e competição.

Por outro lado, valores como qualidade, tradição e reputação se associam significativamente com o número de laços; entretanto, essa relação tem sinal negativo, a julgar pelo coeficiente de Pearson. Indo além da centralidade de grau, a centralidade de intermediação apresenta essas e outras associações. A customização, por exemplo, está correlacionada com a centralidade de intermediação. Logo, atores com capacidade em ligar outros atores entre si podem vir a disseminar mais facilmente a valorização da customização.

Mas apesar de existir relações significativas entre valores e centralidade, faz-se necessário verificar ainda se há diferenças de valores entre os componentes central e periférico da rede. Assim, seria possível verificar se a maior coesão entre os nós do componente central, bem como o baixo número de contatos entre os atores do componente periférico da rede, contribuem para a valorização diferenciada de aspectos que podem estar associados à gestão das organizações religiosas em exame. Para tal análise foi realizado um teste de diferença das médias para os valores do centro e periferia da rede. A tabela 3 apresenta as médias $(\bar{x})$ dos valores para centro e periferia da rede e sua significância estatística ( $p$-value).

Tabela 3

Teste $t$ para valores entre centro e periferia

\begin{tabular}{|lccl|}
\hline & Centro $(\bar{x})$ & Periferia $(\bar{x})$ & p-value \\
\hline V1 - Inserção política & 4,547 & 3,707 & 0,328 \\
V2 - Expansão & 8,178 & 7,781 & 0,400 \\
V3 - Responsabilidade social & 7,726 & 7,614 & 0,829 \\
V4 - Modernidade & 7,426 & 6,552 & 0,231 \\
V5 - Eficiência (gestão) & 7,845 & 5,822 & $0,001^{* *}$ \\
V6 - Customização & 6,547 & 4,970 & $0,044^{* *}$ \\
V7 - Qualidade & 8,916 & 9,385 & $0,026^{* *}$ \\
V8 - Reputação & 8,487 & 9,156 & $0,015^{* *}$ \\
V9 - Tradição & 6,571 & 8,302 & $0,003^{* *}$ \\
\hline
\end{tabular}




\begin{tabular}{|lccc|}
\hline & Centro $(\bar{x})$ & Periferia $(\bar{x})$ & p-value \\
\hline V10 - Cooperação & 8,128 & 7,458 & $0,098^{*}$ \\
V11 - Competição & 5,333 & 4,707 & 0,393 \\
V12 - Mercado & 4,273 & 3,260 & 0,134 \\
\hline
\end{tabular}

Fonte: Dados primários da pesquisa.

** p-value $<0,05$

$*$ p-value $<0,10$

No que diz respeito aos esquemas interpretativos dos agentes localizados no centro e na periferia, as semelhanças residem na lógica de inserção política, expansão da igreja, responsabilidade social, modernidade, competição e mercado. Todavia, os graus de valorização de cada um desses fatores são diferentes. Inserção política, competição e mercado apresentam as médias mais baixas. A postura da direção da central em relação a esses fatores pode justificar tal achado. Quanto à responsabilidade social e à modernidade podese perceber que esses fatores são mais valorizados em relação aos fatores anteriores, mas apresentam médias mais moderadas. A expansão, por outro lado, tem média um pouco mais alta e é valorizada em igual intensidade pelos dois componentes da rede.

Os outros seis fatores que representam o restante dos valores ambientais são os seguintes: eficiência, customização, cooperação, qualidade, reputação e tradição. A valorização da eficiência, da customização e da cooperação é mais elevada no componente central da rede em comparação ao componente periférico. Qualidade, reputação e tradição apresentam médias mais altas na periferia. Os dirigentes das congregações que estão localizados no centro parecem dar maior valor a questões ligadas à gestão do que aqueles dirigentes localizados fora do centro. As lógicas de coordenação e controle, de oferecimento de cultos direcionados a determinados perfis e de realização de atividades conjuntas entre congregações são mais presentes nesse grupo. Esse mesmo grupo valoriza menos questões historicamente tão caras à igreja como a qualidade dos cultos e louvores, a reputação e a tradição da igreja em suas liturgias e costumes. As correlações entre esses fatores reforçam tal assertiva, pois, à medida que um dirigente valoriza mais as questões diretamente ligadas à gestão, menos atenção tende a ser direcionada à qualidade, reputação e tradição.

Para tentar explicar a diferença entre esses valores nos componentes central e periférico da rede, julgou-se adequado verificar a provável influência 
da idade dos dirigentes das congregações sobre os valores em seus esquemas interpretativos. Para tanto, foi realizado o teste $t$.

$O$ resultado indica que existe diferença estatisticamente significativa da média de idade dos membros do centro $(\bar{x}=47,39)$ e da periferia $(\bar{x}$ $=61,13)$ da rede. A diferença de valores dos dirigentes de centro e periferia da rede pode existir em função de possíveis especificidades nos processos de socialização desses atores sociais com idades diferentes. A valorização da eficiência, customização e da cooperação parece estar relacionada à própria institucionalização mais recente do emprego de técnicas administrativas nas organizações religiosas.

Com vistas a identificar de que forma a configuração da rede em exame (conforme dissemos supra, condiciona os valores dos dirigentes) se relaciona às atividades dos dirigentes das congregações, foi empregado o teste qui quadrado $\left(\chi^{2}\right)$ para a proporção das atividades (Wilson e Jarzabkowski, 2004) presentes nos dois grupos da rede. Os resultados para todas as atividades investigadas aparecem na tabela 4.

Tabela 4

Frequência e teste qui quadrado das atividades para centro e periferia

\begin{tabular}{|lccc|}
\hline Atividade estratégica & Centro & Periferia & $p$-value $\left(\chi^{2}\right)$ \\
\hline Culto de empresários & 14,30 & 00,00 & $0,027^{* *}$ \\
Culto de prosperidade & 25,00 & 03,10 & $0,013^{* *}$ \\
Culto da vitória & 50,00 & 28,10 & $0,082^{*}$ \\
Culto de propósito & 21,40 & 15,60 & 0,562 \\
Culto de libertação & 78,60 & 75,00 & 0,744 \\
Culto de milagres & 25,00 & 09,40 & 0,105 \\
Culto de curas & 21,40 & 09,40 & 0,192 \\
Culto de almoço & 14,30 & 03,10 & 0,119 \\
Culto da manhã & 14,30 & 09,40 & 0,554 \\
Culto ao ar livre & 82,10 & 59,40 & $0,055^{*}$ \\
Envio de missionários ao exterior & 53,60 & 43,80 & 0,448 \\
Envio de missionários a outros estados & 71,40 & 43,80 & $0,031^{* *}$ \\
Cursos profissionalizantes & 28,60 & 03,10 & $0,006^{* *}$ \\
Cursos de música & 82,10 & 59,40 & $0,055^{*}$ \\
Curso de alfabetização & 21,40 & 03,10 & $0,028^{* *}$ \\
Cursos de idiomas & 32,10 & 06,30 & $0,010^{* *}$ \\
\hline
\end{tabular}




\begin{tabular}{|lccc|}
\hline Atividade estratégica & Centro & Periferia & p-value $\left(\chi^{2}\right)$ \\
\hline Curso de libras & 28,60 & 03,10 & $0,006^{* *}$ \\
Plantão voluntário na central (sede igreja) & 35,70 & 21,90 & 0,235 \\
Uso de e-mail na evangelização & 57,10 & 28,10 & $0,023^{* *}$ \\
Uso de internet na evangelização & 60,70 & 25,00 & $0,005^{* *}$ \\
Reformas na congregação & 75,00 & 53,10 & $0,079^{*}$ \\
Evangelização nas ruas à noite & 46,40 & 28,10 & 0,142 \\
Cultos em casa de membros & 96,40 & 78,10 & $0,037^{* *}$ \\
Planejamento e realização de retiros & 57,10 & 40,60 & 0,201 \\
Busca de doações com empresários & 03,60 & 03,10 & 0,923 \\
Busca de doações com políticos & 03,60 & 06,30 & 0,635 \\
Campanhas de arrecadação financeira & 00,00 & 06,30 & 0,178 \\
Telefonemas para os ausentes nos cultos & 100,00 & 71,90 & $0,002^{* *}$ \\
Visitas para os ausentes nos cultos & 100,00 & 93,80 & 0,178 \\
Intensos estímulos individuais para batismo & 39,30 & 28,10 & 0,360 \\
Doações de roupas & 89,30 & 81,30 & 0,384 \\
Doaç̦ões de alimentos & 57,10 & 37,50 & 0,128 \\
Divulgação no jornal da central & 67,90 & 37,50 & $0,019^{* *}$ \\
Colaboração no congresso de jovens & 32,10 & 15,60 & 0,131 \\
Relacionamento com políticos & 28,60 & 15,60 & 0,225 \\
Busca de apoio de políticos & 17,90 & 18,80 & 0,928 \\
\hline
\end{tabular}

Fonte: Dados primários da pesquisa.

* p-value $<0,10$

** p-value $<0,05$

Ao observar os resultados do teste qui quadrado, foi possível caracterizar os grupos de centro e periferia a partir da presença/ausência de determinadas atividades em diferentes partes da rede. O grupo de centro se caracteriza e é diferenciado, em relação à periferia, por ser constituído por organizações em que algumas atividades são mais frequentes. Essas atividades são as seguintes: culto dos empresários, culto de prosperidade, culto da vitória, culto ao ar livre, envio de missionários a outros estados, oferecimento de cursos profissionalizantes, cursos de alfabetização, cursos de idiomas, curso de libras, uso de email e internet na evangelização, reformas na congregação, culto em casa de membros, telefonemas para os fiéis ausentes dos cultos e divulgações de suas ações no jornal da central. 
Também é preciso mencionar aquelas atividades que não discriminam um grupo do outro. Essas atividades, que são desempenhadas ou gerenciadas em proporções não diferenciadas estatisticamente centram-se em: culto de propósito, culto de milagre, culto de cura, culto da manhã e de almoço, envio de missionário ao exterior, plantão na central, evangelização nas ruas à noite, realização de retiros, busca de doações com políticos e empresários, realização de campanhas de arrecadação financeira, estímulos individuais ao batismo, visitas para os ausentes dos cultos, doações de roupas e alimentos, relacionamento com políticos, busca de apoio de políticos e colaboração no congresso de jovens da igreja.

Vale lembrar que, de acordo com a visão baseada em atividades, as fontes de valor das organizações se estabelecem nas microatividades dos atores organizacionais (Johnson, Melin e Whittington, 2003), pois o conjunto de atividades organizacionais é o que dá forma e constrói a estratégia (Jarzabkowski, 2004). Ao considerar que as atividades relatadas pelos dirigentes da central efetivamente fazem diferença sobre o resultado das organizações em estudo, é possível inferir que gozam de maior vantagem competitiva as organizações inseridas no componente central da rede.

\section{Considerações finais}

Em relação aos resultados empíricos do trabalho, a amostra em exame permite concluir que a rede de dirigentes das congregações da igreja em exame se caracteriza pela existência de dois grupos principais de atores sociais. A análise da estrutura da rede de relacionamentos revelou dois componentes que representam uma configuração centro-periferia dos padrões de interação entre os pastores pesquisados.

O componente central é caracterizado por pastores mais novos e maior densidade da rede, enquanto o componente periférico apresenta poucas relações entre seus nós, os quais apresentam idade mais avançada. Os dirigentes situados no centro valorizam a eficiência, a customização e a cooperação, ao passo que os atores localizados na região periférica primam por valores mais históricos no âmbito da igreja, como qualidade, reputação e tradição.

Quanto às atividades estratégicas, os dirigentes das congregações do centro da rede realizam com maior frequência: cultos a públicos específicos, envio de missionários para outros estados, atividades de desenvolvimento da comunidade, evangelização com uso da internet, reformas na congregação, 
telefonemas para os fiéis ausentes, cultos na casa dos membros e divulgação no jornal da central. Uma parte das atividades estratégicas desses atores parece reconstruir alguns dos valores mais presentes no componente da rede no qual se localiza o próprio dirigente. Da mesma maneira, esses valores limitam a variedade de ações desempenhadas e coordenadas pelos pastores da central em seu próprio componente.

Assim, a relação entre contexto institucional, estrutura dos relacionamentos e práticas (atividades) estratégicas aponta para a noção de mútua dependência entre esses elementos. Entretanto, destaca-se que essa interdependência é marcada por contradições institucionais (Friedland e Alford, 1991) que reforçam a homogeneidade de algumas práticas e heterogeneidade de outras.

Admitir que o contexto institucional opere em múltiplos níveis amplia as possibilidades de recortes teóricos e analíticos. No caso deste estudo, o contexto institucional foi avaliado em duas esferas. Para tanto, foram propostas e validadas empiricamente as seguintes categorias de análise: contexto institucional de primeira ordem e contexto institucional de segunda ordem.

De forma mais ampla, vale destacar o alto grau da presença de valores ligados à gestão nas organizações religiosas de confissão evangélica que foram tomadas em exame. Logo, a institucionalização desses valores e práticas correspondentes parece estar em franco processo de sedimentação, sobretudo em função da natureza competitiva que opera no entorno das atividades dessas organizações.

Como afirma Miller (2002), é recente o reconhecimento de que as organizações religiosas operam numa lógica concorrencial. Logo, pressões por conformidade e busca de diferenciais competitivos têm conduzido essas organizações à adoção de uma forma organizacional que facilite seu processo de expansão: a organização em rede.

E a despeito dos graus de institucionalização das práticas que reproduzem as regras, normas e pressupostos, a sedimentação desses valores não ocorre de modo homogêneo em todas as organizações de um campo, muito menos nas diferentes unidades de uma rede estratégica.

Assim, o papel da interpretação e a significação tornam-se elementos fundamentais na explicação da ação social. Nesses termos, é preciso compreender de que modo outros atores têm capacidade de influenciar a construção de significados em meio a processos de interpretação, pois são esses processos os responsáveis pelo desencadeamento da ação social. 


\section{Referências}

BABBIE, E. R. The practice of social research. 8. ed. California: Wadsworth Publishing Company, 1998.

BARDIN, L. Análise de conteúdo. Lisboa: Edições 70, 1977.

BARTUNEK, J. M. Changing interpretative schemes and organizational restructuring: the example of a religious order. Administrative Science Quarterly, v. 29, p. 355-372, 1984.

BORGATTI, S. P.; EVERETT, M. G. Models core/periphery structures. Social Networks, v. 21, p. 375-395, 1999.

BURT, R. S. Structural holes: the social structure of competition. Cambridge: Harvard University Press, 1992.

CRESWELL, J. W. Research design: qualitative, quantitative, and mixed methods approaches. 2. ed. London: Sage Publications, 2003.

DACIN, M. T.; VENTRESCA, M. J.; BEAL, B. D. The embeddedness of organizations: dialogue and directions. Journal of Management, v. 25, n. 3, p. 317-356, 1999.

DAFT, R. L.; WEICK, K. E. Toward a model of organizations as interpretation systems. Academy of Management Review, v. 9, n. 2, p. 284-295, 1984.

DIMAGGIO, P. J.; POWELL, W. W. The iron cage revisited: institutional isomorphism and collective rationality in organization fields. American Sociological Review, v. 48, n. 2, p. 147-160, 1983.

FLICK, U. Uma introdução à pesquisa qualitativa. 2. ed. Porto Alegre: Bookman, 2004.

FRIEDLAND, R.; ALFORD, R. R. Bringing society back in: symbols, practices, and institutional contradictions. In: POWELL, W. W.; DIMAGGIO, P. J. (Eds.). The new institutionalism in organizational analysis. Chicago: The University of Chicago Press, 1991.

GIDDENS, A. A constituição da sociedade. São Paulo: Martins Fontes, 1989.

GUILFORD, J. P. Psycometric methods. New York: McGraw-Hill, 1954.

GRANOVETTER, M. Economic action and social structure: the problem of embeddedness. American Journal of Sociology, v. 91, n. 3, p. 481-510, 1985.

HAIR JR., J. F.; ANDERSON, R. E.; TATHAM, R. L.; BLACK, W. C. Multivariate data analysis: with readings. 4. ed. New Jersey: Prentice Hall, Inc., 1995. 
HANNEMAN, A. R. Introduction to social network methods. Riverside: University of California, 2001.

JARZABKOWSKI, P. Strategic practices: an activity theory perspective on continuity and change. Journal of Management Studies, v. 40, n. 1, p. 23-55, 2003.

. Strategy as practice: recursiveness, adaptation, and practices-in-use. Organization Studies, v. 25, n. 4, p. 529-560, 2004.

. Strategy as practice: an activity-based approach. London: Sage, 2005.

JOHNSON, G.; MELIN, L.; WHITTINGTON, R. Micro strategy and strategizing: towards an activity-based view. Journal of Management Studies, v. 40, n. 1, p. 3$22,2003$.

MACHADO-DA-SILVA, C. L.; FONSECA, V.; CRUBELLATE, J. M. Estrutura, agência e interpretação: elementos para uma abordagem recursiva do processo de institucionalização. Revista de Administração Contemporânea, p. 9-39, 2005. edição especial.

MEYER, J. W.; ROWAN, B. Institutional organizations: formal structure as myth and ceremony. American Journal of Sociology, v. 83, n. 2, p. 340-363, 1977.

MILLER, K. D. Competitive strategies of religious organizations. Strategic Management Journal, v. 23, n. 4, p. 435-456, 2002.

POWELL, W. W.; SMITH-DOERR, L. Networks and economic life. In: SMELSER, N. J.; SWEDBERG, R. (Eds.). Handbook of economic sociology. Princeton: Russell Sage Foundation, 1994.

OLIVER, C. The institutional embeddedness of economic activity. In: SHRIVASTAVA, P.; HUFF, A. S.; DUTTON, J. E. (Eds.). Advances in strategic management. Greenwich, Connecticut: Jay Press, 1996. v. 13.

SCOTT, W. R. Institutions and organizations. Thousand Oaks: Sage Publications, 2001.

SYDOW, J.; WINDELER, A. Organizing and evaluating interfirm networks: a structuracionist perspective on network processes and effectiveness. Organization Science, v. 9, n. 3, p. 265-284, 1998.

UZZI, B. The sources and consequences of embeddedness for the economic performance of organizations: the network effect. American Sociological Review, v. 61, p. 674-698, 1996.

. Social structure and competition in interfirm networks: the paradox of embeddedness. Administrative Science Quarterly, v. 42, p. 35-67, 1997. 
WARNER, R. S. Work in progress toward a new paradigm for the sociological study of religion in the United States. American Journal of Sociology, v. 98, p. 1044-1093, 1993.

WASSERMAN, S.; FAUST, K. Social network analysis. Cambridge: Cambridge University Press, 1999.

WHITTINGTON, R. Strategy as practice. Long Range Planning, v. 29, n. 5, p. 731735, 1996.

. Strategy after modernism: recovering practice. European Management Review, v. 1, n. 1, p. 62-68, 2004.

. Completing the practice turn in strategy research. Organization Studies, v. 27, n. 5, p. 613-634, 2006.

WILSON, D. C.; JARZABKOWSKI, P. Thinking and acting strategically: new challenges for interrogating strategy. European Management Review, v. 1, n. 1, p. 14-20, 2004. 